\title{
CONTRIBUIÇÕES INICIAIS SOBRE FUGAS ESCRAVAS E FORMAÇÃO DE QUILOMBOS NA CONFLUÊNCIA DOS RIOS ARAGUAIA E TOCANTINS (MARABÁ, SÉCULOS XVIII-XIX)
}

\author{
Maria Clara Sales Carneiro Sampaio ${ }^{1}$ \\ Marta Lima Alves ${ }^{2}$
}

\begin{abstract}
Resumo: O presente trabalho tem como objetivo apresentar algumas contribuições iniciais sobre a formação sócio-histórica da região de confluência dos rios Araguaia e Tocantins entre finais do século XVIII e início do século XIX, como um território de circulação e resistência de população escrava, em especial, em fuga. A aproximação e encontro dos dois rios abraçam paisagens histórico-sociais complexas e fundamentais para a construção regional da atual região Mesorregião Sudeste do estado do Pará, para a região do Bico do Papagaio do estado do Tocantins (antigo estado Goiás) e para a fronteira entre a mesorregião oeste e a mesorregião sul, no cerrado amazônico maranhense.
\end{abstract}

Palavras-Chave: Araguaia - Tocantins; Quilombos; História Social da Escravidão.

\section{INITIAL CONTRIBUTIONS ON SLAVE LEAKS AND FORMATION OF KILOMBS IN THE CONFLUENCE OF THE ARAGUAIA AND TOCANTINS RIVERS (MARABÁ, 17th AND 18th CENTURIES)}

Abstract: This article aims to offer initial findings on the presence and circulation of runaway slaves in the region of the encounter of the Araguaia and the Tocantins rivers. The better understanding of the impact of African slavery resistance in said region is fundamental to deepen the historical knowledge of the tri state border area, that includes the Southeast Pará, the north of the nowadays state of Tocantins (Bico do Papagaio's region) and the amazon cerrado part of the state of Maranhão, in Brazil.

Key-words: Araguaia-Tocantins; Maroon communities, Slavery.

\section{CONTRIBUCIONES INICIALES SOBRE FUGAS DE ESCLAVOS Y FORMACIÓN DE KILOMBAS EN LA CONFLUENCIA DE LOS RÍOS ARAGUAIA Y TOCANTINS (MARABÁ, SIGLOS XVIII-XIX)}

Resumen: El presente trabajo tiene como objetivo presentar algunos aportes iniciales sobre la formación sociohistórica de la región de confluencia de los ríos Araguaia y Tocantins entre finales del siglo XVIII y principios del XIX, como territorio de circulación y resistencia de la población

\footnotetext{
${ }^{1}$ Maria Clara Sales Carneiro Sampaio é graduada em Direito pela Pontifícia Universidade de São Paulo (PUC-SP, 2001-2005) e em História pela Universidade de São Paulo (USP, 2002-2006). Realizou suas pesquisas de mestrado e de doutorado no Programa de Pós-Graduação em História Social da USP, com período de doutorado-sanduíche na Universidade de Yale (2010-2011) e apoio da Fundação de Amparo à Pesquisa do Estado de São Paulo (Fapesp). Tem experiência em arquivos estrangeiros nos Estados Unidos, Canadá, Caribe Britânico, América Latina, Europa Continental e Reino Unido. É professora do Programa de Pós-Graduação em História (PPGHIST) da Universidade Federal do Sul e Sudeste do Pará (UNIFESSPA). Seus interesses de pesquisa estão relacionados à História da Amazônia, História Atlântica, Teoria da História, Subalternidade e Gênero.

${ }^{2}$ É graduada em História pela UNIFESSPA. Possui especialização em Ensino de História. Atualmente cursa Sociologia pela UNIASSELVI e é mestranda em História pelo PPGHIST-UNIFESSPA.
}

Revista Escritas do Tempo - v. 3, n. 7, jan-abr/2021 - p. 29-46 
esclava, especialmente en fuga. El acercamiento y encuentro de los dos ríos abarcan paisajes históricos y sociales complejos y fundamentales para la construcción regional de la actual región de la Mesorregión Sureste del estado de Pará, para la región Bico do Papagaio del estado de Tocantins (antes estado de Goiás) y para el límite entre la mesorregión occidental y la mesorregión sur, en la sabana amazónica de Maranhão.

Palabras clave: Araguaia-Tocantins; Quilombos; Historia social de la esclavitud.

\section{Introdução}

O presente trabalho tem como objetivo apresentar algumas contribuições iniciais sobre a formação sócio-histórica da região de confluência dos rios Araguaia e Tocantins entre finais do século XVIII e início do século XIX, como um território de circulação e resistência de população escrava, em especial, em fuga. A aproximação e encontro dos dois referidos rios abraçam paisagens histórico-sociais complexas e fundamentais para a construção regional da atual Mesorregião Sudeste do estado do Pará, para a região do Bico do Papagaio do estado do Tocantins (extremo norte do antigo Goiás) e para a fronteira entre a mesorregião oeste e a mesorregião sul, no cerrado amazônico maranhense.

Figura 1 - Bacia do Tocantins-Araguaia

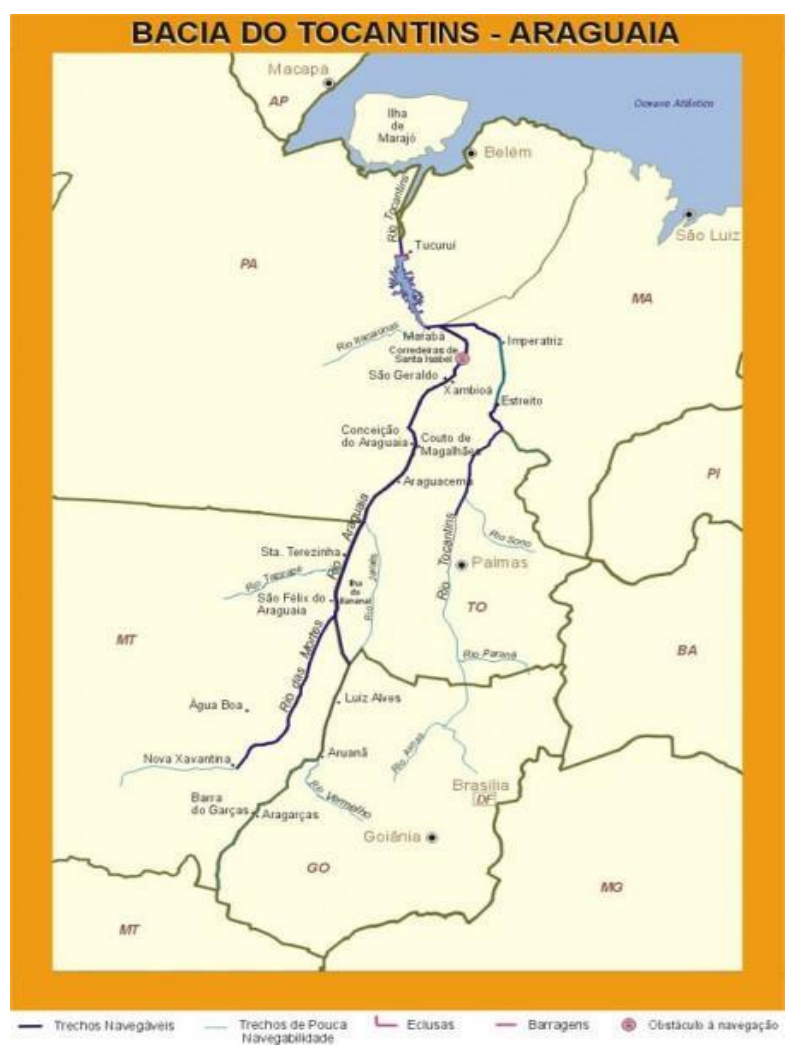

Fonte:

https://www.gifex.com/imapa/americas/small/Mapa_Portos_Hidrovias_Bacia_TocantinsAraguaia_Brasil.jpg

Revista Escritas do Tempo - v. 3, n. 7, jan-abr/2021 - p. 29-46 
$\mathrm{O}$ encontro dos dois rios marca a tríplice fronteira entre os referidos estados e engloba o município de São João do Araguaia, no Pará, o município de Esperantina, no Tocantins, e o município de São Pedro da Água Branca no Maranhão. São João do Araguaia, junto com Tucuruí (antiga Alcobaça), está entre os municípios mais antigos do Sudeste paraense e, segundo o Instituto Brasileiro de Geografia Estatística (IBGE), tem uma população estimada de 14.051 pessoas até $2020^{3}$.

A população estimada para São Pedro da Água Branca, para 2020, é um pouco menor, somando 12.735 habitantes $^{4}$. A cidade de Esperantina, no Tocantins, tem a população estimada em 11.139 pessoas $^{5}$. Tratam-se de municípios pouco populosos, mas que se encontram no escopo de influência regional de cidades médias, como é o caso da cidade de Marabá (PA) e da cidade de Imperatriz (MA), ambas com mais de 250 mil habitantes, também segundo estimativas para 2020 do IBGE.

Mais do que as cidades mencionadas, o eixo Araguaia-Tocantins engloba outros municípios e, desde o período colonial, é visto por diferentes autoridades luso-brasileiras como um ponto de grande importância geoestratégica não apenas para a demarcação das fronteiras internas, mas como uma via de comunicação fluvial a ser sempre melhor explorada em prol de uma maior integração entre as costas fluviais e atlânticas da calha norte e das regiões do centro-sul do Brasil. A região era relativamente conhecida por populações não indígenas desde meados dos 1600:

...foram os jesuítas PP. Antônio Vieira, Francisco Velloso, António Ribeiro e Manoel Nunes que, entre 1633 e 1658 empreenderam quatro entradas, Tocantins acima. A fim de descerem índios para as aldeias do Pará. Já na primeira dessas viagens, passaram além da boca do Araguaia. A entrada do P. Manoel, realizada com 450 índios das missões de 45 soldados, no ano de 1658 , foi além de $8^{\circ}$ de latitude sul, portanto, precisamente, até o território dos Apinayé (...) Em 1673, o bandeirante paulista Pascoal Pais de Araujo desde com sua tropa pelo Tocantins até mais ou menos $40^{\circ}$ de latitude sul (...) Em 1719 o Rio Araguaia foi navegado pelo jesuíta Domingos Pinto de Gaya, que depois subiu também o Tocantins, segundo diz, até $12^{\circ} 22^{\prime}$, portanto, quase até a confluência com o Paranã (...) Em 1721 o Tocantins foi navegado pelo P. Manoel Motta. (NIMOENDAJÚ, 1983, p. $01)$.

\footnotetext{
3 As informações sobre o município de São João do Araguaia estão disponíveis em: https://cidades.ibge.gov.br/brasil/pa/sao-joao-do-araguaia/panorama, e foram consultadas em: $17 \mathrm{dez}$. 2020.

4 As informações sobre o município de São Pedro da Água Branca estão disponíveis em: https://cidades.ibge.gov.br/brasil/ma/sao-pedro-da-agua-branca/panora e foram consultadas em $17 \mathrm{dez}$. 2020.

5 As informações sobre o município de Esperantina estão disponíveis em: https://cidades.ibge.gov.br/brasil/to/esperantina/panorama e foram consultadas em 17 dez. 2020.
}

Revista Escritas do Tempo - v. 3, n. 7, jan-abr/2021 - p. 29-46 
A questão da navegação fluvial em ambos os rios, faz-se importante mencionar, era de tal ordem de importância que foi oficialmente proibida por boa parte do século XVIII. Com o aumento da exploração da mineração de ouro em Goiás, as rotas que ligavam a região das minas a Belém se mostraram extremamente difíceis para se policiar o contrabando:

Até 1782, o tráfego do comércio de Goiás, via fluvial, com o Pará, estava proibido devido ao contrabando de ouro. Com o declínio da mineração e a crise econômica que se abatera na Província de Goiás, os dois grandes rios - Araguaia e Tocantins - passam a ser considerados escoadores naturais do sertão goiano; o caminho mais indicado para o desenvolvimento do comércio de integração com as vastas regiões do Brasil. Foi um período em que o governo imperial deu andamento à conquista de novos espaços territoriais em vários rios das bacias hidrográficas brasileiras. (CARVALHO e CAVALCANTE, 2010, p. 4)

A questão da navegabilidade do Araguaia e do Tocantins foi tema de importantes decisões políticas em diferentes momentos da história colonial, imperial e republicana do Brasil. O estudo já clássico de Dalísia Martins Doles (1969) percorre os diferentes interesses estratégicos acerca da navegação dos dois rios nos 1600 e 1700, evidenciando o papel dos bandeirantes do Sul e da penetração de missões religiosas (em geral jesuítas), que entravam majoritariamente pelo Maranhão. O governador e capitão-mor do GrãoPará e Maranhão entre 1671-1678, por exemplo, demonstrou preocupação em melhorar o mapeamento do Tocantins e Araguaia: “Ainda no século XVII duas entradas organizadas pelo governador do Pará, Pedro César Menezes, sobem o Tocantins" (DOLES, 1969, 252).

Com a decadência da economia mineradora em Goiás e, mais tarde, com a independência do Brasil, foram ampliados os esforços de busca por maior integração entre a antiga província de Goiás e Belém (SALGADO, 2019). Foi apenas na segunda metade do século XIX, contudo, que as companhias de navegação e a navegação a vapor receberam maior atenção e investimentos, principalmente sob a direção de José Vieira Couto de Magalhães, após sua Viagem ao Araguaya, publicado pela primeira vez em 1863.

Revista Escritas do Tempo - v. 3, n. 7, jan-abr/2021 - p. 29-46 


\section{Amazônia, Escravidão e Historiografia}

Antes de prosseguirmos, faz-se necessário apontar que a disponibilidade ainda limitada de estudos sobre a escravidão africana no eixo Araguaia-Tocantins pode ser um reflexo de questões historiográficas mais amplas. Como nos ensina a historiadora Patrícia Melo Sampaio, a historiografia sobre a escravidão negra na região amazônica tem crescido muito nas últimas décadas e mostra cada vez mais panoramas complexos e diversificados. O crescimento de uma pungente historiografia social da escravidão africana amazônica tem, contudo, em regra, privilegiado outras localidades, como e o caso do entorno daquelas que se tornaram as capitais provinciais e estaduais, quais sejam, Belém, Manaus e São Luís. Também privilegiam as localidades ligadas às calhas do Amazonas, Negro, Tapajós, Purus e Trombetas, entre outras.

As trajetórias de pesquisa de Vicente Salles, Eurípedes Funes, Flávio dos Santos Gomes e Patrícia Sampaio, dentre outros pesquisadores e pesquisadoras, ainda, lançaram algumas das bases para o crescimento de uma historiografia sobre experiências de escravidão negra na Amazônia que, muitas vezes, divergem das tendências seguidas pelas experiências do tráfico e da escravidão que marcaram a história do trabalho escravo de outras regiões brasileiras, uma vez que “As populações desembarcadas no Pará faziam parte de etnias distintas, capturadas na rede comum dos mercadores de almas" (SAMPAIO, 2003, p. 5).

Contudo, a presença crescente de africanos no Pará coloca em movimento questões mais amplas que não podem ter suas dimensões avaliadas apenas em função do número de escravos disponíveis porque o que está em jogo, é a própria montagem e reiteração de uma sociedade hierarquizada, com escravos, cuja lógica de reprodução não se limita ao número de almas disponíveis nos plantéis, mas antes se traduz na reiteração de relações de subordinação e poder que dão vida ao próprio sistema. Isso, sem dúvida, é uma realidade importante que deve ser adequadamente considerada. Além disso, tais estudos sinalizam que, a despeito da entrada "tardia" de africanos, as características do comércio internacional e as formas de inserção no mundo do trabalho permitiram a emergência de uma sociedade na qual índios e africanos de diferentes procedências se misturaram intensamente (...) Também é importante destacar, como já fez Rafael Chambouleyron, que "a idéia de que a relação plantations/escravidão africana e a experiência do nordeste açucareiro representam um modelo ideal, dificulta a compreensão da experiência do Estado do Maranhão no século XVII. (SAMPAIO, 2003, p. 4).

Para além dos nexos de circulação e fugas escravas do Alto e Médio Tocantins, bem como provenientes do sul do Maranhão, faz-se necessário, ainda, pensar nos

Revista Escritas do Tempo - v. 3, n. 7, jan-abr/2021 - p. 29-46 
fugitivos e fugitivas provenientes do Baixo Tocantins. Ademais, já no século XIX, outra reflexão importante é aquela sobre a pouca produção historiográfica a respeito dos efeitos que a repressão à Cabanagem (1835-1840) teve na região de confluência dos rios Araguaia e Tocantins. Conquanto a interiorização dos revoltosos no Alto e no Baixo Amazonas já conte com vasta bibliografia, faz-se necessário compreender melhor os efeitos da revolta no entorno do encontro dos referidos rios.

Para adquirir toda esta confiança e controle de si, foi necessária muita experiência de luta e esta não se encerrou com a retomada de Belém pelos "legalistas". Depois disto, os cabanos ainda viveram uma saga pelos rios e igarapés da imensa calha do Amazonas, do Madeira e do Tocantins, em um movimento de fuga e de interiorização da luta armada. Estes revolucionários fugitivos abriram outras frentes de luta, ampliaram suas bandeiras e alteraram as formas de guerrear. Aprenderam a usar a natureza a seu favor, envenenando rios, queimando a mata, espantando os animais e dizimando plantações de alimentos básicos para a subsistência das tropas inimigas, como a mandioca e o milho. Seus avanços fizeram muito alarde no médio, no alto Amazonas e nos rios Negro e Trombetas, entre os anos de 1836 e 1837. Revolucionaram cidades como Santarém, Manaus e toda a região até a fronteira com o atual estado do Amapá. Também rumaram para a calha dos rios Tocantins e Madeira, indo em direção ao Maranhão e ao Piaú. Deixaram atrás de si uma Amazônia cabocla que exaltava o poder das novas lideranças. (RICCI, 2007, p. 28)

Como nos ensinou a historiadora Magda Ricci, as profundas mudanças sociais que solaparão diferentes regiões amazônicas no pós-Cabanagem, já em meados do século XIX, também devem fazer parte das reflexões sobre constituição sócio-histórica do eixo Araguaia-Tocantins. Acreditamos que qualquer reflexão sobre o eixo AraguaiaTocantins, destarte, precisa partir da perspectiva de que nesse espaço não se encontram apenas os referidos rios, mas múltiplas populações, interesses e realidades. Trata-se de um espaço de encontro, de passagem e de resistência de escravizados e escravizadas fugindo de diferentes realidades de escravidão, que parecem conflagrar as múltiplas experiências amazônicas do atual estado do Pará, das fronteiras de cultivo do Maranhão e do extremo norte da antiga província de Goiás.

\section{Rios e Resistência}

Seguindo essa lógica, o presente trabalho partiu da análise da região do AraguaiaTocantins a partir da perspectiva de confluência de pelo menos 3 eixos mais conhecidos pela historiografia no tocante à presença e à circulação escrava. Não estamos excluindo

Revista Escritas do Tempo - v. 3, n. 7, jan-abr/2021 - p. 29-46 
outras possibilidades de origem ou outras zonas de contato, mas temos nos centrado na busca e análise de documentos dessas três frentes de pesquisa ${ }^{6}$. Até o momento a pesquisa documental, interrompida pela pandemia da Covid 19, não nos permitiu postular sobre a presença de escravarias substantivas nessa área, mas a presença de quilombos na região é conhecida, como nos mostra o militar e geógrafo português Antônio Ladislau Monteiro Baena (1782-1850), em sua obra Ensaio Corográfico sobre a Província do Pará, de 1839, endereçada ao governador em Belém:

São João de Araguaia: registro instituído em 1797, e situado entre a Praia do Tição e o Seco do Bacabal sobre uma ribanceira da margem direita do rio Tocantins à vista da foz do rio Araguaia, que lhe demora na parte oposta acima dele. Este registro apresenta umas casas palhaças colocadas com independência de toda a disposição regular, nas quais assistem o comandante, os soldados, o cirurgião e o capelão. Ele foi estabelecido não só para baldar os extravios do ouro, as fugas dos escravos de Camutá para Goiás, e as agressões dos Timbiras, Carajás e Apinagés, habitantes das margens daquele rio, mas também para refocilamento das pessoas, que empreendem tão trabalhosa viagem através daquela vasta extensão selvagem, bruta. (BAENA, 2004, p. 252)

Baena $^{7}$, ao descrever o entreposto militar de São João do Araguaia, que recebeu diferentes investimentos e tratamentos nos períodos colonial e imperial, como veremos mais adiante, nos abre uma janela para uma melhor compreensão da contínua necessidade das autoridades luso-brasileiras em marcar sua presença (ainda que pequena) das na região, com o objetivo, entre outros, de inibir as fugas escaravas e o estabelecimento de quilombos. Seu apontamento aparentemente é indicativo de um potencial fluxo de fugas escravas das regiões do Baixo Tocantins, que englobam as porções central e norte do Pará, para as zonas sertanejas goianas. A presença de um ou mais quilombos na região

\footnotetext{
${ }^{6}$ Faz-se importante mencionar o estudo de Antônio Liberac Simões Pires que ligam algumas comunidades quilombolas do atual Tocantins a migrações provenientes do nordeste do país. (PIRES In: OLIVEIRA, 2006, p. 156. E também a pesquisa de mestrado de André Nicácio Lima (2010, p. 78).

${ }^{7} \mathrm{O}$ historiador Antônio Alexandre Isídio Cardoso no ensina: A segunda metade do século XIX foi um período de grandes transformações no território amazônico. Passados os tempos lutuosos da Cabanagem (mas não seus desdobramentos), houve uma série de tentativas de reorganização dos mundos do trabalho da Floresta. Em 1850 foi criada a Província do Amazonas, desmembrada do Pará, que se tornou lócus oficial do esquadrinhamento do alto curso da calha norte e dos seus habitantes. Antes da implementação da nova unidade do Império, o Major Antonio Ladislau Monteiro Baena traçou estimativas demográficas de Lugares, Vilas e Missões que ajudariam a conformar parte da futura província. Segundo o censo, levantado desde o início da década de 1830 e somente publicado em 1839, a área alcançava a cifra de 17.881 livres e 962 escravos. O contraste entre a grande porção geográfica e o pequeno contingente populacional deixava entrever que os habitantes das florestas, sobremaneira indígenas não-aldeados e fugitivos, não entraram no cômputo total. Estes transitavam fora dos enclaves oficiais, figurando como personagens intangíveis aos cálculos populacionais". (CARDOSO, 2017, p. 33).
}

Revista Escritas do Tempo - v. 3, n. 7, jan-abr/2021 - p. 29-46 
tem aparecido, ainda que de maneira lateral, em pesquisas mais recentes como a da historiadora Maria Aparecida de Oliveira Lopes (2009

Os quilombos do século XVIII estavam localizados em Três Barras, Tocantins, Arraias, Meia Ponte, Crixás e Paracatu. Registra-se, ainda, a presença de pelo menos um quilombo na região do Bico do Papagaio, ente os rios Araguaia e Tocantins. (LOPES, 2009, p. 104)

Lopes, contudo, parece dar maior enfoque ao influxo contrário: de escravizadas e escravizados fugidos da região do Alto Tocantins em direção ao Pará. O tema da presença escrava, fugas e formação de quilombos na região abrangida pelo norte da capitania de Goiás já conta com uma historiografia mais bem sedimentada (DOLES, 1973; SALLES, 1992; KARASCH, 2009; LOIOLA, 2009), como nos aponta a historiadora estadunidense Mary Karasch (1996):

Em outras áreas, existiam ainda matas extensas no século XVIII, especialmente no norte, entre os rios Araguaia e Tocantins, onde os quilombolas eram frequentemente localizados e atacados, principalmente nas florestas que margeavam fazendas e engenhos. Assim, os escravos tinham disponíveis florestas densas, montanhas inexploradas, cerrados espinhosos, manguezais infestados por mosquitos, ilhas escondidas, inúmeros rios e muita distância dos brancos tinham, enfim, locais onde levantar quilombos e viver em liberdade. (KARASCH In: REIS e GOMES [orgs.], 1996, p. 245.)

Pensando o fluxo de fuga na mesma direção, qual seja Goiás-Pará, a análise de Karasch (1996), sobre a formação de quilombos no século XVIII, na região do Bico do Papagaio, confronta múltiplas fontes coloniais com estudos antropológicos sobre comunidades indígenas da região, entre outros documentos, para pontuar a recorrência de existência de quilombos desde o eixo Araguaia-Tocantins até a região de Alcobaça, atual município de Tucuruí, mais ao Norte.

Um quilombo mais ao norte, que possivelmente tinha laços com os fugitivos das vilas mineiras da região de Tocantins, se localizava em Pederneiras, acima de Alcobaça e da atual cidade de Marabá. Quando o antropólogo Curt Nimuendujú estudou os Apinajés na década de 1930, foi informado de que eles haviam uma vez assaltado os quilombolas de Pederneiras, no finar do século XVIII, com o objetivo de conseguir ferramentas de trabalho. Um documento do século XVIII se refere a ataques a escravos fugidos feitos por "gentios" da região do rio Tocantins. Quando os índios (os Apinajé?) os capturaram, cortaram-lhes as cabeças e em seguida as expuseram suspensas em postes fincados nas margens do rio. Para impedir seus ataques, foram levantados fortes em Alcobaça, em 1780, e nas cachoeiras de Arapary em 1791. Mesmo assim, os Apinajé continuaram a atacar Pederneiras, que foi então abandonada. Assim acabou a história de um

Revista Escritas do Tempo - v. 3, n. 7, jan-abr/2021 - p. 29-46 
povoado que um dia fora o sítio de "um grande mocambo de escravos fugidos chefiados por uma mulher". Outras tradições locais registram a presença de pelo menos um quilombo na região do Bico do Papagaio, entre os rios Araguaia e Tocantins - deve-se imaginar que os escravos escondiam-se nas densas matas dessa região longo do rio do Sono, onde o quilombo ganhava o nome de Mumbuca, nome indígena de uma espécie de abelha. (KARASCH In: REIS e GOMES [orgs.], 1996, p 246-247)

O pioneiro estudo do antropólogo Curt Unckel Nimuendajú (1883-1945) sobre os Apinajés, da década 1930, aponta a preponderâncias dessas comunidades indígenas na região do "pontal entre o Rio Tocantins e o Baixo Araguaia, estendendo-se ao sul, mais ou menos, até $6^{\circ} 30^{\prime}$. E de se supor que, temporariamente, tenham ultrapassado esses limites, pelo lado Noroeste" (NIMUENDAJÚ, 1983, p. 1). A resistência dos Apinajé, bem como de outras comunidades indígenas da região, fez-se conhecida pelos ataques a outra região de quilombo, mais ao norte, já no Baixo Tocantins:

Em Pederneiras ( $\left.3^{\circ} 30^{\prime}\right)$, na margem esquerda, existiu um grande mocambo de escravos fugidos. Em 1779 foi transformado em colônia. Os Apinayé aparecem pela primeira vez com esse nome, em fins do sáculo XVIII. Faziam então correrias, Tocantins abaixo, para apoderarem-se de ferramentas. Em consequência dessas hostilidades fundou-se em Alcobaça com seis peças de artilharia, e, depois em 1791, um outro posto junto à primeira cachoeira, no Arapary. Pederneiras, devido às incursões dos índios foi abandonada. (NIMUENDAJÚ, 1983, p. 2)

A reconstituição histórica feita por Nimuendajú dos Apinajé nos propicia a possibilidade de pensar outra dimensão de trocas socioculturais entre o eixo AraguaiaTocantins (indo até a região de Alcobaça). Tanto via o contato violento entre Apinajés e os quilombolas próximos a Alcobaça, como em sua hipótese de que foram escravizados fugidos da mineração em Goiás que "Em 1732 o Tocantins foi navegado em todo seu curso pela primeira vez, por três fugitivos das minas de Goiás". (NIMUENDAJÚ, 1983, p. 2). A leitura de Karasch nos auxiliou na interpretação dos escritos de Nimuendajú:

A fuga de canoa ou jangada era facilitada por três grandes rios - o Araguaia a oeste, o Tocantins a leste e o Paranaíba ao sul - ligados a inúmeros afluentes. 'Os primeiros não-índios a navegar todo o curso do Tocantins' foram três negros fugidos das minas de Goiás, em 1723. (KARASCH In: REIS e GOMES [orgs.], 1996, p. 244).

As formações quilombolas mencionadas por Karasch, ainda no período colonial, podem potencialmente também guardar relação com as fugas das escravarias do sul do 
Maranhão, como nos aponta a historiadora Idelma Santiago da Silva para o início do século XIX:

Na Amazônia Oriental brasileira, a existência de mocambos que reuniram negros e índios foram comuns tanto no Pará como no Maranhão. Nos sertões de Pastos Bons, por exemplo, as descrições de [Francisco de] Paula Ribeiro (1819) dão notícias de que os índios abrigavam negros fugidos da escravidão. (SILVA, 2014, p. 209).

Antes de refletirmos sobre as descrições do militar português Francisco de Paula Ribeiro, em suas viagens pelo sertão maranhense, no início do século XIX, alguns apontamentos se fazem necessários. O conceito de caldeirão social amazônico oitocentista foi emprestado das pesquisas do historiador Antônio Alexandre Isídio Cardoso (2017). A complexa região amazônica, que Cardoso chama de Eldorado dos Deserdados, apresenta-se como um panorama riquíssimo de sociabilidades que somavam às inúmeras comunidades indígenas, mestiças e luso-brasileiras, toda sorte de desertores, fugitivos, africanas e africanos-livres, mestiços, escravizadas e escravizados fugidos e migrantes de pertenças variadas.

Ainda que a pesquisa de Cardoso faça referência a outras territorialidades amazônicas, mais ao norte, entendemos que nossa região de estudo, qual seja, o eixo Araguaia-Tocantins, tenha dinâmicas sócio-históricas semelhantes às regiões do Alto e Baixo-Amazonas entre fins do século XVIII e a primeira metade do século XIX.

O temor diante dos "inimigos do público", em grade medida desertores militares e escravos fugidos, era agravado pela rarefeita eficácia da vigilância ante um mundo de águas e matas ainda parcamente esquadrinhado. $\mathrm{O}$ ralo conhecimento oficial sobre os melindres das territorialidades locais, com seus infindáveis igarapés, furos, igapós e léguas de trilhas nativas ainda insondadas, convertia-se em grave empecilho aos que pretendiam perseguir fugitivos. (CARDOSO, 2017, p. 19).

A descrição de Cardoso faz menção às redondezas da foz do rio Negro, em 1830, contêm pontos de aderência com algumas das descrições de Paula Ribeiro, cerca de 15 anos antes. Como podemos ler abaixo:

Aquelles gentios que por mais fracos perdem suas possessões, não há que sujeitarse e unir-se aos vencedores para desfrutar com estes o terreno; é preciso largalos, e ir ganhar outro além do Tocantins, único recurso que lhes resta agora; e por isso é que sua multidão naquellas vastas extenções do Pará e de Goyaz, se fazem impenetráveis à nossa investigação, e também difíceis ao augmento da população, e cultura que aquellas capitanias procuraram estabelecer nessas partes (PAULA RIBEIRO, 1841, p. 186)

Revista Escritas do Tempo - v. 3, n. 7, jan-abr/2021 - p. 29-46 
O excerto, em nossa compreensão, parece descrever a região de encontro dos rios Araguaia e Tocantins e parece corroborar com o que Cardoso chama de "ralo conhecimento oficial sobre os melindres das territorialidades locais" e que concorriam para que fosse um "grave empecilho" para o acesso ao que o militar lusitano caracterizava como os "extensos desertos de areia” que dividiam os rios da região (PAULA RIBEIRO, 1841, p. 245).

Como nos mostra Silva (2014), ainda que Paula Ribeiro pareça privilegiar a descrição das diferentes nações indígenas, acaba por descrever comunidades mestiças, envolvendo escravas e escravos fugidos, dentre outros indivíduos provenientes das mais diversas origens e pertenças, que procuravam a floresta para desbravá-la ou se esconder nela. A relação entre diferentes comunidades indígenas com escravizados em fuga é bastante complexa e toma diferentes formas a depender da geografia, da temporalidade e das condições de negociação - sempre violentas e desiguais - impostas pelas autoridades coloniais e, depois, nacionais (CARDOSO, 2017).

Até o momento, tem se privilegiado as relações entre Goiás e Pará no itinerário de pesquisa. O contato com a historiografia e com as fontes maranhenses, sem dúvida, nos proporcionarão outras muitas análises.

\section{À Margem do Controle}

As formas como as diferentes autoridades luso-brasileiras pensaram o eixo Araguaia-Tocantins nos períodos colonial e imperial nos oferecem múltiplos fatores para refletir sobre o aspecto do controle que se desejava ter sobre os rios e as populações que residiam e circulavam pela região. A questão da fundação de entrepostos militares e presídios, nesse aspecto, nos oferece muitas oportunidades para pensarmos de maneira mais aprofundada a circulação de populações consideradas indesejadas por esses poderes locais e centrais.

O cruzamento de diferentes fontes documentais sobre a presença militar, ainda que comparativamente pequena, em São João do Araguaia, nas inúmeras esferas de reflexão sobre a formação da memória do local como uma espécie de zona de contato entre a representação dos poderes coloniais - e depois nacionais - e de um mundo de sujeitos subalternos, à margem da ordem e do controle representados pela colonização e pela evangelização.

Revista Escritas do Tempo - v. 3, n. 7, jan-abr/2021 - p. 29-46 
A questão de uma maior integração entre Norte e Sul, passando pela mediação dos poderes provinciais e pelo conhecimento mais profundo sobre a navegação tanto do Tocantins quanto do Araguaia, permanecerá como um tópus nas narrativas políticas por muitas e muitas décadas. A pesquisa de Doles nos permite observar as tentativas de costura política entre Pará e Goiás nas décadas finais dos 1700.

A liberação da navegação é tentada pelo governador D. João Manue', mas não se concretiza em virtude de sua morte em 1770. Embora a proibição perdurasse, o governador de Goiás, D. José de Almeida Soveral de Carvalho mandou estudar as possibilidades de navegação pelo Araguaia e Tocantins, tendo êle próprio percorrido êste último, atingindo o rio Claro (...) Parece que havia intenção de uma ação cônjunta dos governos de Goiás e Pará no sentido da liberação da circulação pela bacia tocantínia. Pelo menos é o que se conclui através da leitura da correspondência entre João Pereira Caldas, governador do Pará e D. João Manuel de Melo. (DOLES, 1969, p. 253-254)

Quase 80 anos depois, na fala do presidente da Província do Grão-Pará à Assembleia Legislativa Provincial, de 1 de outubro de 1848, Jerônimo Francisco Coelho descreve suas dificuldades de se obter informações exatas sobre a abertura de uma “estrada de communicação com Goyaz, margeando o Tocantins, obra esta tão desejada, e meditada desde remotas eras" tanto por parte do "Commandante do Destacamento de S. João de Araguaia", como por parte do governador da Província de Goiás. (COELHO, 1848, p. 86). A maior integração interprovincial entre Goiás e Pará permanecia como um desafio político, e a navegação fluvial conectando as províncias do Norte às do CentroSul do Brasil, um sonho, talvez, não tão distante.

Informado de que alguns fazendeiros da Proyincia de Goyaz, do Districto da Bôavista, extrema com o territorio do Pará, procurando estabelecer-se nos campos centra es correspondentes á margem direita do Alto Tocantins, e já em terras do Pará, acabaõ de descobrir um rio navegavel denominado Santa Anna, que pela abundanecia de suas agôas e direcçaõ de sua corrente, faz presumir que seja algum dos tributarios do Rio Capim, ou as cabeceiras deste, pois nesse caso, e se fôr desempedido em todo o seu curso, se prestará elle a uma facil e prompta navegação interior até sahir na foz do Guamá, trato de levar a effeito uma exploraçaõ, descendo-se pelo rio descoberto até se verificar ao certo a direcçaõ do seu curso, e para esse fim, por intermedio do Cidadaõ Antonio Gonçalves Neves, residente na BôaVista, e que a pouco esteve nesta Capital, fiz remessa de varios artigos de munições e ferramen tas, a fim de que, de intelligencia com os ditos fazendeiros, se proceda as precisas averiguações, autorisando mais qualquer despeza. Que se faça com esta deligencia, e gratificando os exploradores, porem somente no caso de que elles venhaõ a surgir no Guamá ou Capim. Neste sentido officiei ao Commandante do Presidio de S. João de Araguaya para prestar urna escolta aos exploralores, e toda a coadjuvaçaõ possivel; e cumpre, aguardar o resultado. (COELHO, 1849, p. 140-141)

Revista Escritas do Tempo - v. 3, n. 7, jan-abr/2021 - p. 29-46 
A fala do mesmo presidente da Província do Grão-Pará, no ano seguinte, em 1848, destaca que outra possibilidade de navegação conectando Goiás a Belém recebeu todo o seu apoio e escolta do comandante do presídio de São João do Araguaia. Ainda que os frutos dessa exploração não tenham sido os esperados, a importância do eixo AraguaiaTocantins se consolidara no ideário político como uma região estratégica, continuamente pouco policiada pelas autoridades e se sedimentando sobre a memória de ser um lócus de fugas escravas, contrabando de ouro e o lar de nações indígenas resistentes à "pacificação". Uma outra regionalidade, talvez, do que Cardoso chamou de Eldorado dos Deserdados.

Anos mais tarde, em 1856, Sebastião do Rêgo Barros, que passava a presidência da Província do Grão Pará para Henrique Beaurepaire-Rohan, reclamava das poucas colônias militares estabelecidas no Pará, a de nome Pedro $2^{\circ}$ (no atual Amapá), a de Óbidos e a de São João do Araguaia, bem como de outras questões:

A Colônia de Obidos progride não obstante os tropeços que tem encontrado pela falta de algumas machinas já há muito encomendadas pelo Governo Imperial, e pala má escolha dos Colonos contractados. As de Pedro $2^{\circ}$ e Araguaya prometem pela sua posição, se forem dirigidas e protegidas, prosperar e ser de grande vantagem para a Provincia (BARROS, 1856, p. 16)

Vimos no registro de Baena, mais acima, a datação de 1797 para a presença militar em São João do Araguaia ${ }^{8}$. Já no relato dos anos 1930, do psiquiatra e sanitarista paulista Júlio Paternostro (1908-1950), de nome Viagem ao Tocantins, publicado como o volume 248 da Série 5 da Brasiliana (Biblioteca Pedagógica Brasileira), em 1945, a datação obedece a outras determinações dos documentos históricos consultados:

Em 1804, o Governador do Grão-Pará, determinando as funções do pôsto militar de São João do Araguaia, esclarecia: - 'É um registro para baldar os extravios de ouro, para impedir a fuga dos escravos de Cametá para Goiás e as agressões dos Timbiras, Carajás e Apinagés'. (PASTERNOSTRO, 1945, p. 137.)

Os relatos de Baena e de Pasternostro são separados por mais de um século. É provável, também, que o último tenha lido o primeiro. Ainda assim, é interessante notar

\footnotetext{
${ }^{8}$ Sobre a presença militar em São João do Araguaia, é sabido, faz-se necessário consultar diferentes sobre Joaquim Teotônio Segurado.
}

Revista Escritas do Tempo - v. 3, n. 7, jan-abr/2021 - p. 29-46 
como ambos possivelmente tiveram acesso a diferentes documentos e, muito provavelmente, a memórias compartilhadas de temporalidades distintas que sedimentam a presença militar em São João do Araguaia como uma espécie de fronteira simbólica entre um mundo ligados às esferas de poder e dos interesses coloniais e, supostamente, nacionais, frente a um mundo subversivo, cheio de sujeitos perigosos, onde o controle não conseguia se enraizar.

Como mencionado na introdução, o presente artigo contém apenas alguns dos primeiros resultados de uma pesquisa maior que carece da consulta de diferentes arquivos locais e estaduais. Ainda assim, podemos supor que a importância estratégica do mapeamento e da navegação Araguaia e do Tocantins se solidifica com os interesses de Couto de Magalhães e de Alfredo Maria Adriano d'Escragnolle Taunay (1843-1899), o Visconde de Taunay, na segunda metade do século XIX. Para os interesses da presente pesquisa, contudo, talvez as fontes que mostrem diferentes formas de contato dentre esses tantos grupos indesejados que moram e passam pelo eixo Araguaia-Tocantins ganhe prevalência entre os temas a serem mais aprofundados em seguida.

Nossa hipótese, até o momento, é que encontraremos algumas respostas nas interações entre diferentes sociedades indígenas e comunidades quilombolas no corredor tocantíneo entre São João do Araguaia e Alcobaça. Como Nimuendajú, Paternostro, viajava a região nos 1930 e faz menção a fugas escravas condizentes aos relatos históricos recolhidos entre os Apinajés.

\footnotetext{
Alcobaça originou-se de um pôsto militar instituído em 1782 pelo Governador do Pará, Teles de Menezes. A finalidade era domesticar índios, aprisionar escravos fugitivos, contrabandistas de ouro que desciam das minas goianas e matogrossenses, pela via natural de comunicação entre o Centro e o Norte - o rio Tocantins. Quarenta anos depois existia no local apenas uma cruz tosca de madeira que mal se distinguia numa clareira quase retomada pelo mato. O povoado ressurgiu mais tarde, e, em 8 de agôsto de 1931 (...) Atualmente, é um distrito do município de Marabá e pôrto de embarque de castanhas. (PASTERNOSTRO, 1945, p. 87)
}

Terminamos o texto, mas não a pesquisa, com as impressões do governador do Pará sobre as nações indígenas a serem catequizadas pela missão chefiada pelo frei carmelita Manoel Procópio do Coração de Maria, considerado um dos fundadores da colônia militar de Santa Thereza, que depois veio a se tornar a cidade de Imperatriz, no Maranhão. O conhecimento acerca das diferentes sociedades indígenas mencionadas aponta para os Apinajés como conhecedores dos caminhos de navegação do Tocantins e do Araguaia e como partícipes do comércio fluvial. $\mathrm{O}$ acesso a outras fontes documentais

Revista Escritas do Tempo - v. 3, n. 7, jan-abr/2021 - p. 29-46 
permitirá, talvez, inserir no enfrentamento entre Apinajés e os quilombolas de Pederneiras interesses provinciais, missionários, comerciais e de outras comunidades locais buscando permanecer fora das esferas de controle.

\begin{abstract}
Vai elle incumbido de missionar e aldêar onde fôr mais conveniente, e segundo a opportunidade das circunstancias, as tribus, que habitaõ naõ só as margens do rio Tocantins, mas as do seu confluente Araguaya, até onde chegaõ as extremas desta Provincia com a de Goyaz. Entre essas tribus contaõ-se a dos Jacundás, Cupelobos, Caraús, e Carajás, que saõ pacificas, e inoffensivas, alem das dos ferozes e traiçoeiros Gaviões, e dos ainda pouco familiarizados Cracatys. Trez grandes aldêas tambem existem de Indios Apinagés, que saõ de todos os mais pacificos, os mais civilizados e de mais antigo tracto, e que frequentemente descem ao porto desta Capital, e que muito auxiliaõ o serviço fluvial das canôas de cornmercio, que navegaõ pelo Tocantins e Araguaya. (COELHO, 1849, p. 140-141).
\end{abstract}

\title{
Referências
}

APOLINÁRIO, Juciene R. Escravidão Negra no Tocantins colonial, vivências em Arraias (1739-1800). Goiânia: Kelps, 2000.

ALMEIDA, José Jonas. Do extrativismo à domesticação: as possibilidades da castanhado-pará. Tese (Doutorado em História Econômica), Universidade de São Paulo, São Paulo, SP, 2014.

BAENA, Antônio Ladislau Monteiro. Ensaio corográfico sobre a Província do Pará. Brasília: Senado Federal, 2004. Disponível em: https://www2.senado.leg.br/bdsf/bitstream/handle/id/1097/714619.pdf?sequence=4\&is Allowed=y, consultado em: 12 out. 2020.

BARROS, Sebastião do Rêgo. Exposição apresentada pelo Exmo. Senr Conselheiro Sebastião do Rego Barros, Presidente da Província do Gram-Pará, ao Exmo. Senr Tenente Coronel d'Engenheiros Henrique Beaurepaire-Rohan, no dia 29 de maio de 1856, por ocasião de passar-lhe a administração da mesma província. Belém: Typographia de Santos \& Filhos, 1856. Disponível em formato digital no Center fos Research Libraries (http://ddsnext.crl.edu/), com o identificador fcf8f1-508b-4e66-84a7c6ad42df8b4b. Consultado em: 10 out. 2020.

CARDOSO, Antonio Alexandre Isídio. O Eldorado dos Deserdados: Indígenas, escravos, migrantes, regatões e o avanço rumo ao oeste amazônico no século XIX. Tese (Doutorado em História Social), Universidade de São Paulo, São Paulo, SP, 2015.

CARVALHO, Francisquinha Laranjeira e CAVALCANTE, Maria do Espírito Santo Rosa. Rio Araguaia: o caminho dos sertões. História Revista, Goiânia, v. 14, n.02, p. 01 $16,2010$.

COELHO, Jeronimo Francisco. Falla dirigida pelo Exmo Sr. Jeronimo Francisco Coelho, presidente da Província do Gram-Pará à Assembléa Legislativa Provincial na Abertura da Sessão Ordinária da sexta legislatura, no dia $1^{\circ}$ de outubro de 1848. Belém: Typographia de Santos \& Filhos, 1848. Disponível em formato digital no Center fos

Revista Escritas do Tempo - v. 3, n. 7, jan-abr/2021 - p. 29-46 
Research Libraries (http://ddsnext.crl.edu/), com o identificador 5d4446b4-7e85-46f4a999-91221c19213. Consultado em 10 out de 2020.

COELHO, Jeronimo Francisco. Falla dirigida pelo Exmo Sr. Jeronimo Francisco Coelho, prezidente da Província do Gram Pará a Assembléa Legislativa Provincial na Abertura da Segunda Sessão Ordinária da sexta legislatura, no dia $1^{o}$ de outubro de 1849. Belém: Typographia de Santos \& Filhos, 1849. Disponível em formato digital no Center fos Research Libraries (http://ddsnext.crl.edu/), com o identificador e2160e216014-4d24-a-160-5832c6fabf66. Consultado em: 10 out. de 2020.

COUTO de MAGALHÃES. José Vieira. Viagem ao Araguaya. Goyaz: Typographia Provincial, 1863. Disponível em: https://digital.bbm.usp.br/handle/bbm/200, consultado em: 05 dez. 2020.

DOLES, Dalísia E. M. A ligação centro-norte pela via Araguaia-Tocantins no Período Colonial. Anais do V Simpósio Nacional dos Professores Universitários de História (ANPUH). Campinas: ANPUH, setembro 1969, p. 251-262.

DOLES, Dalísia E. M. As comunicações fluviais pelo Tocantins e Araguaia no século XIX. Goiânia: Oriente, 1973.

FUNES, Eurípides A. Nasci nas matas, nunca tive senhor: História e memória dos mocambos do Baixo Amazonas. Tese (Doutorado em História Social), Universidade de São Paulo, São Paulo, SP, 1995.

GOMES, Arilson dos Santos. Migrações, populações negras e representações em Marabá, Sudeste do Pará (1913-1983). Saeculum, João Pessoa, v. 40, n. 40, p. 196-215, 2019.

GOMES, Flávio dos Santos. Em torno dos Bumerangues: Outras Histórias de Mocambos na Amazônia Colonial. Revista USP, São Paulo, n. 28, p. 40-55, dez.-fev.,1995-1996.

GOMES, Flavio dos Santos. Quilombos e Mocambos no Brasil (Sécs. XVII-XIX). Tese (Doutorado em História). Universidade Estadual de Campinas, Campinas, SP, 1997.

GOMES, Flávio dos Santos. "No Labirinto dos rios, furos e igarapés": camponeses negros, memória e pós-emancipação na Amazônia, c. XIX-XX. História Unisinos, São Leopoldo, v. 10, n. 6, p. 281-292, 2006.

HARRIS, Mark. Rebellion on the Amazon: the Cabanagem, race, and popular culure in the north of Brazil, 1798-1840. Cambridge: Cambridge University Press, 2010.

KARASCH, Mary. Os quilombos do ouro na capitania de Gioás. In: REIS, João José e GOMES, Flávio dos Santos (Orgs.). Liberdade por um fio, a história dos quilombos no Brasil. São Paulo: Companhia das Letras, 1996.

KARASCH, Mary. Central Africans in Central Brazil, 1780-1835. In: HEYWOOD, Linda M. (orgs.). Central Africans and cultural transformations in the American diaspora. Cambridge: Cambridge University Press, 2002. p. 117-153.

Revista Escritas do Tempo - v. 3, n. 7, jan-abr/2021 - p. 29-46 
LIMA, André Nicácio. Caminhos da integração, fronteiras da política: a formação das províncias de Goiás e Mato Grosso. Dissertação (Mestrado em História Social) Faculdade de Filosofia, Letras e Ciências Humanas, Universidade de São Paulo. São Paulo, 2010.

LOBATO, Mateus Monteiro e EMMI, Marília Ferreira. Migração na fronteira: um encontro de trajetórias sociais em Marabá-Pará. Caminhos de Geografia, Uberlândia v. 15, p. 20-36, 2014.

LOIOLA, Maria L. Trajetórias para a liberdade: escravos e libertos na Capitania de Goiás. Goiânia: Editora da Universidade Federal de Goiás, 2009.

LOPES, Ionete Morais. Dinâmicas culturais no Sudeste Paraense: um estudo de narrativas orais de migrantes castanheiros. Dissertação (Mestrado em Estudos Literários), Universidade Federal de Minas Gerais, Belo Horizonte, MG, 2015.

NIMOENDAJO, Curt. Os Apinayé. Belém: Museu Paraense Emílio Goeldi, 1983.

OLIVEIRA LOPES, Maria Aparecida de. Experiências Históricas dos Quilombos no Tocantins: organização, resistência e identidades. Patrimônio e Memória, Assis, v. 5, n. 1, p 99-118, out., 2009.

PALACÍN, Luis. O século do ouro em Goiás. 4a ed. Goiânia: Editora da Universidade Católica de Goiás, 1994.

RICCI, Magda. Cabanagem, cidadania e identidade revolucionária: o problema do patriotismo na Amazônia entre 1835-1840. Tempo, Niterói, v. 11, n. 22, p.5-30, 2007.

PASTERNOSTRO. Viagem ao Tocantins. Edição Ilustrada. São Paulo: Companhia Editora Nacional, 1945.

PAULA RIBEIRO, Francisco de. Roteiro da Viagem que fez o Capitão Francisco de Paula Ribeiro às fronteiras da Capitania do Maranhão e da de Goyaz no anno de $1815 \mathrm{em}$ serviço de S. M. Fidelíssima. Jornal do Instituto Histórico Geográfico Brasileiro, Rio de Janeiro, Tomo X, p. 5-80, $1^{\circ}$ Trimestre de 1848.

PIRES, Antônio Liberac Simões. Notas etnográficas sobre as comunidades negras rurais do Tocantins. In: OLIVEIRA, Rosy. Socialibilidades negras, comunidades remanescentes, escravidão e cultura. Belo Horizonte: Daliana, 2006.

RODRIGUES, Jovenildo Cardoso. Marabá: centralidade urbana de uma cidade média paraense. Dissertação (Mestrado em Planejamento do Desenvolvimento), Universidade Federal do Pará, Belém, PA, 2010.

SALGADO, Tathiana Rodrigues. Atividades comerciais durante o período colonial em Goiás - Brasil. Mercator (Fortaleza), Fortaleza, v. 18, e18015, 2019 . Disponível em: $<$ http://www.scielo.br/scielo.php?script=sci_arttext\&pid=S1984-

22012019000100211\&lng=en\&nrm=iso >. Consultado em: 28 abr. 2021.

Revista Escritas do Tempo - v. 3, n. 7, jan-abr/2021 - p. 29-46 
SALLES, Vicente. O negro no Pará sob o regime da escravidão. Rio de Janeiro/Belém do Pará: Fundação Getúlio Vargas, 1971.

SALLES. Gilka Vasconcelos Ferreira de. Economia e escravidão na Capitania de Goiás. Goiânia: Editora da Universidade Federal de Goiás, 1992.

SAMPAIO, Patrícia Melo. Nas Teias da Fortuna: acumulação mercantil em Manaus, século XIX. Mneme (Revista de Humanidades), Caicó, v. 3, n. 6, p. 49-70, out.-nov., 2002.

SANTOS, Fabiano Vilaça dos. Os capitães-mores do Pará (1707-1737): trajetórias, governo e dinâmica administrativa no Estado do Maranhão. Topoi. Rio de Janeiro, v. 16, n.31, p. 667-688, Dec. $2015 . \quad$ Disponível em: $<$ http://www.scielo.br/scielo.php?script=sci_arttext\&pid=S2237-

101X2015000200667\&lng=en\&nrm=iso>. Consultado em: 18 abr. 2021.

SCHWARCZ, Lília Moritz e GOMES, Flávio dos Santos. Amazônia Escravista. In: Dicionário da Escravidão e da Liberdade: 50 textos críticos. São Paulo. 2018.

SILVA, Idelma. Santiago da. A migração como mito fundador e outras metáforas: narrativas da colonização no sudeste do Pará. Escritas, Araguaína, v. 2, p. 59-74, 2010.

SILVA, Idelma. Santiago da. Fronteira Cultural: A alteridade maranhense no sudeste do Pará (1970-2008). Tese (Doutorado em História), Universidade Federal de Goiás, Goiânia, GO, 2010.

SILVA, Idelma. Santiago da. Migração e Cultura no Sudeste do Pará: Marabá (19681988). Dissertação (Mestrado em História. Universidade Federal de Goiás, Goiânia, GO, 2006.

SPIVAK, Gayatri C. Pode o subalterno falar? Belo Horizonte: Editora da Universidade Federal de Minas Gerais, 2010.

VELHO, Otávio Guilherme. Marabá da castanha e do diamante. Rio de Janeiro: Centro Edelstein de Pesquisas Sociais, 2009.

Artigo recebido em 01 de fevereiro de 2021. Aprovado em 30 de abril de 2021.

Revista Escritas do Tempo - v. 3, n. 7, jan-abr/2021 - p. 29-46 